Full length article

\title{
The powerful combination of cross-country comparisons and life-history data
}

\author{
James Banks ${ }^{\mathrm{a}, \mathrm{b}, *}$, Agar Brugiavini ${ }^{\mathrm{c}, \mathrm{b}}$, Giacomo Pasini ${ }^{\mathrm{c}, \mathrm{d}}$

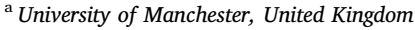 \\ ${ }^{\mathrm{b}}$ Institute for Fiscal Studies, United Kingdom \\ ${ }^{\mathrm{c}} \mathrm{Ca}$ ' Foscari University of Venice, Italy \\ ${ }^{\mathrm{d}}$ NETSPAR, Netherlands
}

\section{A R T I C L E I N F O}

\section{Keywords:}

International comparisons

Late-life employment

Life-history data

\begin{abstract}
A B S T R A C T
In this paper we discuss the value of international comparative empirical studies within the broad field of the economics of ageing. We argue the value is particularly great when such comparative research is based on long life-history data on participants, collected using large-scale autobiographical life-history methods. We identify particular aspects of such comparisons that create value relative to other empirical methods and also briefly survey recent key papers to illustrate each aspect. Finally we provide a short new application of this method, using data from SHARE and ELSA, to look at the question of how labour markets for older workers in Europe have been changing across cohorts and the extent to which this has been associated with changing retirement ages in public pension systems.
\end{abstract}

\section{Introduction}

International comparisons are becoming a commonly used empirical method in the economics of ageing, partly because of increasing availability of detailed comparable data from multi-disciplinary longitudinal studies of ageing that have been specifically designed for such purposes. But simply documenting how circumstances differ in old age around the world, whether this is in terms of health, social and family circumstances or economic position, is not particularly useful. Good international comparative research needs to be meaningful enough to inform us about what is driving the evolution of outcomes over the lifecourse in different countries and why. For example, it needs to show the role of policy variables and institutions, the environment (broadly defined), or life course trajectories more generally, in determining how different types of individual in different countries end up with the latelife outcomes that they do.

This paper argues that international comparisons based on retrospectively collected life-history information can be particularly valuable in this respect. We discuss the relatively recent innovation of largescale standalone retrospective life-history data collection that has now been added to a number of ageing studies around the world, including the English Longitudinal Study of Ageing (ELSA), the Survey of Health and Retirement in Europe (SHARE). We argue that such life-history data provide a number of advantages. Firstly, researchers using these studies have access to life-course data on more cohorts and hence can exploit more policy variation and policy reforms in their analysis. Second, and related, having complete life-course trajectories 'observed' means that researchers can exploit opportunities to link early life exposures to late life outcomes and can carry out trajectory analysis or estimate dynamic panel models with much longer time-series on each individual. Finally, a unique attribute of life-history data is that they cover periods of an individual's life when they were not in their current household, marriage, or partnership, which can be useful when looking at complex issues surrounding marital selection and sorting. ${ }^{1}$

Finally, and most substantively, as an illustration of the potential value of such data we present some simple new analysis using retrospective life-history on labour market trajectories in twelve European countries for all cohorts born between 1920 and 1959. We take two example questions - namely (a) how important are state retirement ages determining late-life work around Europe? and (b) to what extent

\footnotetext{
* Corresponding author.

E-mail address: james.banks@manchester.ac.uk (J. Banks).

${ }^{1}$ An additional value of such data collection, unrelated to issues of international comparison, is in situations where, due to the sampling design, current partners of

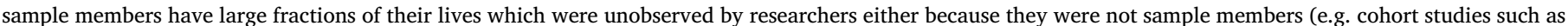

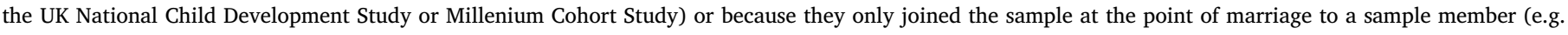
income panels such as the PSID or Understanding Society).
} 
is the labour market becoming more flexible for older workers? - to motivate our analysis. As a starting point, we are able to easily replicate the previous findings of one of the first and most important international comparisons in the economics of ageing, namely the Gruber and Wise $(1999,2004)$ studies that showed, using different countries and a shorter time period, the importance of state pension institutions in determining employment at older ages. We then go on to show the value of having additional data on the entire trajectory of employment at older ages for different cohorts, as opposed to just cross-sectional data or short panel sequences on work as in the Gruber-Wise studies. We show that, once we condition on whether or not the individual is working at age 50, there are to all intents and purposes no differences in the labour market trajectories of men and women, nor in the way that they are affected by public pension retirement ages. We can also go on to measure the total number of years of work supplied after age 50 as an indicator of late-life work and show, for the first time to our knowledge, how this has been evolving across different cohorts in different countries. In an attempt to suggest some preliminary evidence on cohort trends and international differences in labour market flexibility at older ages, we show that the average number of jobs held after age 50 has been rising steadily across cohorts, although the degree to which this has been happening is very different across Europe.

The paper is structured as follows. In the next section we briefly set out the reasons why international comparisons are considered particularly valuable in ageing research and use this framework to show why international comparisons based on life-history data have so much analytical potential. In section three, we highlight some of the methodological background and innovations underlying the design and collection of such life-history questionnaires, and discuss issues around the validation of such data and methods. Section four provides a brief and partial survey of some of the most promising examples of comparative life-history methods, as a way of illustrating the kind of applications that are possible. As pointed out in this section, the majority of these studies are modelling health or wellbeing outcomes as the endpoint, life-history data have not yet been used extensively for labour market research. Consequently, to illustrate the potential value of such a method, in section five we carry out an analysis of the life-history trajectories for employment in two major ageing surveys covering twelve European countries and discuss the findings that emerge. Section six concludes.

\section{Revisiting the value of international comparisons in ageing research}

There is an understanding amongst researchers and policymakers involved in the economics of ageing that to best understand the issues surrounding demographic change and population ageing one needs to first understand the way that individual circumstances and choices evolve over the life-cycle. Analysis that is aimed at delivering evidence on the causes and consequences of health, family and socioeconomic events in an individual life-course, is of high value to policymakers and researchers alike. And such analysis usually needs to exploit some kind of variation in institutional factors that individuals face in order to estimate causal effects. Since there is typically much greater variation between countries than within, it is unsurprising that some researchers turn to international comparisons when estimating their models. For a recent survey of international comparative studies in health and ageing studies, for example, see Banks and Smith (2012).

Methodologically, international comparisons are no different to any other geographical comparisons, such as those that exploit variation across US states. One country is implicitly being used as a counterfactual for another. The identification issues, if one is to look to understand causal effects of a policy change or other life-course events, are the same as in within-country studies, relating to non-random selection or compliance into the treatment, spillovers between control and treatment groups, and potential pre-policy differences. But the factors or assumptions behind these threats to identification are likely to hold to different degrees if we consider countries instead of other smaller regions. Necessary assumptions relating to the absence of policy-driven migration across borders and a lack of spillovers across the areas being studied are probably easier to maintain in international comparative studies than in within-country analysis. On the other hand, the requirements for there to be common data and measurement protocols in the areas being studied and data which is comprehensive enough to control for all the other relevant factors that might be driving differences between regions, is considerably more challenging.

Over the last twenty years the international research community in ageing and health, facilitated by funding from the US National Institute of Aging, has made major leaps forward in designing and collecting data that is comprehensive enough, and comparable enough such that researchers now have more data and better data with which to carry out international comparisons. The detailed harmonised data that has been generated by the close cooperation between the US Health and Retirement Study, the English Longitudinal Study of Ageing and the Survey of Health, Ageing and Retirement in Europe has now been extended to many more countries around the world including China, Japan, India, Brazil, South Africa and many more and this is changing the opportunities for researchers wanting to carry out empirical studies on ageing. ${ }^{2}$

Such international comparable data, and the empirical analyses they facilitate, are particularly important in ageing research, where it is long run life-course trajectories that are the key object of interest, and where there is general agreement that the key trajectories over the lifecourse (e.g. physical, biological, psychological, economic, and social) are integrally linked and dynamically evolving. When late-life outcomes are the object of study, many other methods of investigation become more problematic. Randomised control trials, experimental policy evaluation or other ex-post evaluation methods can be difficult since researchers would need to wait long periods of time in order to measure the outcomes of interest. ${ }^{3}$ Moreover it is currently infeasible to construct structural models with sufficient complexity and granularity in all dimensions in order to simulate the effect of policy or other factors on late-life outcomes.

Given these considerations, there is a clear premium on comparable data that cover as much of individuals life-cycles as possible. Life-history studies (which we will denote by LH from now on) are large-scale standalone data collection exercises designed to collect data on events that people experienced in their whole life-course and how these have shaped choices and affected the well-being of individuals. They allow the researcher to measure cumulative effects of specific determinants on outcomes and to assess the long-run consequences of external shocks on outcomes late in life. This has clear benefits even within single country analyses. Firstly, they allow researchers to link early life exposures to late life outcomes without waiting for prospective data. Second, they provide complete measures of life-time exposures and behaviours. Third, they create much longer time-series for each individual and hence open up possibilities for more data-intensive and potentially robust quantitative methods. Finally, they tell us about the times both before and after the individual was living in their current demographic arrangements, which may be useful for analyses where household composition, dynamics and behaviours are important.

In the context of international comparisons, the value of such lifehistory methods, is particularly great. Whilst there is already more cross-section variation in institutions between countries than within countries, if one considers the full history of institutional variation and

\footnotetext{
${ }^{2}$ See the Gateway to Global Aging data www.g2aging.org for more details.

${ }^{3}$ One exception here is when interested in interventions targeted at older age individuals with the intention of ameliorating potential adverse circumstances and changing the direction of trajectories given particular levels of earlier-life disadvantage.
} 
the general experience of historical events that exists over the life-times of older adults around the world this is even greater, and offers huge opportunities for analysis. With data on the full life-times of older people we can study the long-run consequences of effects of events or policy changes that happened many years ago, using countries that did not experience such events or changes as either informal or formal counterfactuals. Such data therefore provide considerable opportunities to deploy the now standard quasi-experimental methodologies such as difference in difference estimators, synthetic control, matching studies or event history studies, or even full dynamic panel data models. It is the ability to carry out such analysis for older cohorts that provides the greatest benefits to researchers in the field of ageing. Hence a large amount of effort by those now working on international comparisons in the areas of the economics of ageing is being devoted to collecting, harmonising and analysing the life-history data of older adults around the world. It is these efforts that are the main topic of what follows.

\section{Life-history questionnaires - methods and quality}

There is an element of past recall in many survey questions. For example, individuals might be asked about their past education, or about health family or economic changes that have occurred since the respondent was previously contacted. Such questions have been common elements, for example, of well-established surveys such as the British Household Panel Study, the German Socioeconomic Panel or the US Panel Study of Income Dynamics. Advances in the understanding of the way in which individuals recall their lives, coupled with new methods of interviewing, led to improvements in the way such recall questions were designed within such longitudinal studies. The work of Belli (1998) on autobiographical memory, for example, was important in changing the design of the Panel Study of Income Dynamics (PSID) measures of employment events between waves. Belli et al. (2001) used a subsample of PSID respondents to demonstrate that an Event History Calendar (EHC) method performed better than standard sequential recall for capturing various socioeconomic changes between waves. ${ }^{4}$

The EHC method targets concerns that retrospective data may suffer from a recall bias - answers may lack precision in terms of timing and places because memory may fade with time. Graphical or visual devices can be a valuable aid in pinpointing relevant dates and can improve the quality of answers on past events. Event History Calendars (EHC) exploit this idea: life events are recorded into a calendar-grid, where a set of events such as children-births, partners, jobs or work experience are combined with the time dimension, usually displayed on the horizontal axis. The grid presents as many rows as there are dimensions to be recorded, so that the respondent and the interviewer can see the life unfolding on parallel lines, as time flows. Each event triggers memories, which help recording events also in other dimensions (Belli, 1998) and in addition salient cultural, social or economic events can be placed onto the grid to aid recall of the precise timing of life-events.

The international family of ageing studies developed tools to build EHC methods into large and complex computer assisted interview modules in order to apply them to large samples. The benefits of such methods are immediately clear since the ageing studies first interview their respondents at age 50 at the earliest, a point where many important events in life have already occurred and life-course trajectories have already been shaped. The English Longitudinal Study of Ageing developed a standalone life-history interview to be delivered to all respondents, and collaborations with the Survey of Health Retirement and Ageing in Europe then led to the development of a similar,

\footnotetext{
${ }^{4}$ At the same time, long-form autobiographical recall was being used on a small scale in the age-65 year follow up of the Boyd-Orr cohort, a sample of British children who were initially assessed in 1937-39. Martin et al. (2005) give details of the full historical cohort follow up and Blane (2005) describes the autobiographical methods employed.
}

although somewhat enhanced, instrument to be delivered to SHARE respondents. These ELSALIFE and SHARELIFE surveys collect retrospective information about the lives of ELSA and SHARE respondents combining a life-grid EHC with retrospective recall questions on early life circumstances in a CAPI mode. The methodology allows for a full reconstruction of important aspects of the prior life of individuals which then gets directly coded into the CAPI data-files and can be merged with other waves of data on the sample members.

Following the innovations of Blane (2005) respondents are allowed to fill in the grid non-linearly and in whatever order suits them. To take the example of the default order, however, the questions might start with questions about children, i.e. year of birth of the oldest child, his or her name, gender, etc. This information gradually appears on the grid for both the respondent and the interviewer to see, and can be used to assist the respondent when thinking about the timing of other events, and even to anchor the wording of subsequent questions such as: Did you live there after your second child was born? or Were you still with $X$ when you moved? Once the timing of events has been established using the life-grid, follow up questions on those events, or further background questions on more general early-life situation and circumstances can be asked. These standard recall questions can also be included in regular waves of the longitudinal studies (as is the case for HRS and SHARE) but are thought to work particularly well in a LH context when the respondent is already engaged in detailed recall and reflection on their life history.

ELSALIFE was fielded in 2007 on the whole ELSA sample that had been interviewed in wave 3 in the previous year. Shortly after, the SHARELIFE component of SHARE was delivered in 2008 in the thirteen countries that were part of SHARE at that time. A second SHARELIFE wave was carried in 2016-2017 (wave 7) and was implemented on the refresher samples of the existing countries and on the new SHARE countries, to cover 28 countries altogether. ${ }^{5}$ Taken together these data provide a vast amount of information on the lives of Europeans ranging from Denmark and Sweden, where the welfare state covers individual against all sorts of risks, to countries like Italy and Greece, where the general view is that the family provides informal insurance. Furthermore, the labour market in Europe is a patchwork of different rules, also reflected in very different systems of pension provisions, unemployment and invalidity benefits. These differences across countries and cohorts provide an ideal ground to study life-course events and their impact on the various dimensions of well-being. Consequently, subsequent to the collection of the raw data from respondents, LH data can be usefully combined with contextual policy variables, for example information about compulsory schooling policies, retirement ages, and disability benefit provisions which can all be associated with each individual/ age/place record in the data.

\section{Potential biases in life-history data: recall and selectivity}

The natural concern with retrospective data, even when collected with the best life-history methods, is the potential existence of recall biases. A number of papers have provided evidence on the validity of the EHC retrospective data, at least in some relevant dimensions. Havari and Mazzonna (2015) investigate whether the survey respondents in SHARE are able to recall with accuracy events, which happened in a distant past and assess the internal and external consistency of some measures of childhood health and socio-economic status. By comparing individual responses with aggregate data (e.g. GDP per capita) at country level, the authors conclude that, on average,

\footnotetext{
${ }^{5}$ In addition, while it is not used in this paper, life-history data has subsequently been collected in ageing studies in the US (HRS), China (CHARLS) and Korea (KLoSA) with all data collection being based on some kind of calendar methods (although in the US these methods were modified for implementation in a leave-behind questionnaire). See www.g2ageing.org for further details.
} 
respondents have an accurate recollection of their health status and living conditions between ages 0 and 15. In a specific validation study Brown (2013) analysed a small module of questions on early life situation that had been taken from the ELSALIFE questionnaire and fielded to members of the UK 1958 National Child Development Study which had collected similar information at the time the sample members were young. The recall of a large majority of respondents was accurate, although it was noted that those with the most unstable or complex early life situations where the recall was least good.

With a similar design, Bingley and Martinello (2017) explicitly model the possible measurement error in earnings data collected in SHARE over the life course. Their validation study is carried out by linking the SHARELIFE respondents to the Danish administrative registers, which contain the true information on earnings histories. They find that measurement error in income is classical once accounting for possible sources of distortions in the administrative data and, by and large, that the information on the schooling experience is not biased.

Finally, although using different studies and different questionnaires, recent work in longitudinal surveys of young adults has compared retrospective reports of adverse childhood experience with prospective measures that were collected on the same individuals in previous waves of the study (Reuben et al. (2016) and Newbury et al. (2018) for example). Independent variation in prospective and retrospective measures is documented with only slight to fair agreement between reports of childhood maltreatment, for example. However, the studies argue a role for both measures since they typically capture nonoverlapping populations and the strongest associations with subsequent psychiatric problems were with the retrospectively recalled measures.

One other important aspect of LH data has been less well investigated and relates to the potential bias of the resulting sample. The fact that data on the entire trajectory is collected at a single point in time makes the LH data considerably more straightforward to work with since researchers do not need to deal with unbalanced panels, attrition and non-response as they typically do with prospectively collected longitudinal data. Nevertheless, if only certain types of respondent are likely to participate in the retrospective LH data collection then these benefits may well be offset by costs in terms of sample representativeness. Moreover, when LH data are collected at considerably older ages these costs may be non-negligible since differential levels of survival to older ages within the cohort is likely to be correlated with some of the processes that are being investigated. Such biases are hard to control for but can be investigated by a cohort-based comparison of population averages of retrospectively reported variables to those that were observed for that cohort at the time. We give an example of this in our application below.

Clearly much more work needs to be carried out to evaluate the validity of retrospective data in general, and document how this validity might depend on the precise LH methods used as well as the particular domains that are being studied and analysed. Indeed, we will carry out some of this in the domain of labour market histories in what follows below. However, the message we take from the studies to date is that there is certainly some value and quality to the data, particularly when used in a way that is sensitive to its design, strengths and weaknesses. Given the considerable analytical potential of such data, such work should be prioritised and then fed back into any design of future retrospective $\mathrm{LH}$ data collection.

\section{Existing studies}

Early-life data, whether collected retrospectively in regular waves of longitudinal ageing studies, or through standalone LH interview components of such surveys, have already been used extensively to document the correlations between early life circumstances and late life outcomes. A vast literature now documents the relationship between childhood health, SES and various measures of early life adversity and outcomes such as lifetime earnings, physical and mental health at older 
ages. Our purpose here is not to document the multitude of such studies nor their findings in any systematic or comprehensive way. Instead we simply highlight a studies that have recently emerged demonstrating the particular value of such early-life data when the life-histories cover such a large and diverse set of cohorts as those currently at older ages in Europe, and when the data contain detailed measures of both health and economic circumstances. With such wide variation across cohorts and across space, researchers have been able to exploit exogenous or quasi-exogenous variation in early-life exposures that make such studies particularly convincing when it comes to identifying causal effects. These papers are listed in Table 1 along with a brief description of the source of variability used in each study.

As a good example of papers showing the long-run health and socioeconomic consequences of early life health and health risks, a number of studies use the differential experiences of war-time cohorts around Europe to look at the effects of early-life shocks on late life health, and particularly the role of hunger in early life in such mechanisms. Using detailed LH data on birth cohort and location during childhood, researchers have linked the LH data with contextual geographical and historical data on rationing and food consumption over time, that can either be used directly in empirical analysis or as an instrumental variable for early life health and self-reported hunger (Table 1, studies 1, 2 and 3). Similarly, adverse events such as the Great Smog of 1952 has been used to create differential exposures within England, which are shown to predict asthma and reduced measured lung-function of individuals at risk in their older ages (Table 1, study 4). In the economics domain, variation in public policies, which have taken place over time and in different countries, have been used to assess the impact on individual's economic decisions at older ages (study 5).

A substantively different application of LH data to life-course health and SES analysis can be seen in recent attempts to look at the linked health trajectories of couples and correlations between the health and economic circumstances of married couples at older ages. The fact that LH data can, as described above, provide information on both members of a partnership in the years before they had met generates possibilities for analysis that are not present in conventional observational studies of married couples, particularly with regard to dealing with issues around assortative mating, shared health behaviours and spillovers between the health status and behaviours of individuals within a couple (Table 1, studies 6 and 7).

The studies mentioned so far have focused on using LH data to identify the effects of early life - whether at the individual or the couple level - on later life outcomes. Whilst they show the power of LH data in combination with international variation in current and historical events and socioeconomic institutions, they still leave considerable potential of the LH data unexplored. Specifically, they have not exploited much of the within-person life-course variation that is observed in the LH data. Indeed, there are far fewer such studies of this type in the literature, not least because the data manipulation and methods to carry out such longitudinal analysis is more demanding. Even within the small set of studies that do model and analyse trajectories more explicitly, most create somewhat simplified summary statistics to describe life-course exposures rather than use the timing of events in any structured way. For example, individuals are classified into a small number of types, using sequence or cluster analysis, according to the pattern of these trajectories. The "types" can be used as risk-factors for late-life outcomes in order to understand the mediating effects of life-course trajectories as mediators of the effect of early life exposures on late life outcomes events (Table 1 studies 8 , 9). An important point of this approach is to show that the impacts of early-life health on the LH trajectories themselves are one of the ways that early life conditions affect health in later life.

The final type of analysis that is beginning to emerge models the events in the LH trajectories with a full dynamic longitudinal analysis at the individual level. Studies are relatively few, to our knowledge, and those that do exist mainly focus on health outcomes, as opposed to labour market outcomes. In such models, the precise timing of specific events in the trajectory, such as economic recessions (Table 1 study 10), or welfare reforms (Table 1 study 11), can be used as exogenous variables in a late-life outcome equation. Whilst such events are relevant objects of study in their own right, the methodological novelty of these papers is to use their length, timing in life and cumulative exposure in the life trajectory to look at the impact on lifetime resources or health outcomes in old age. Taking the example of welfare policies, the study of the protective effects of maternity leave benefits and child support policies, granted to the mother at the time of childbirth, on depression and mental health at old age, specifically considering the stress often suffered by mothers after childbirth. It requires modeling the detailed timing of labour market interruptions and the timing and spacing of childbirths as well as knowledge of health circumstances at different points in the trajectory, the generosity and timing of policy interventions and the measurement of ex post outcomes: a wealth of information that can be gained only through a fully-fledged event study of LH surveys.

\section{Labour market dynamics after age $\mathbf{5 0}$ across European cohorts}

ELSALIFE and SHARELIFE respondents are asked to report a number of characteristics regarding each job spell over the life course life, i.e. covering the time from when they finished full time education up to the time of the interview. Observations can then be organized as an individual-level dataset where job spell characteristics are reported in successive sets of variables numbered accordingly. In this paper we follow the approach developed by Brugiavini et al. (2013) for SHARELIFE to create a Job Episodes Panel encompassing both ELSALIFE and SHARELIFE. The starting point are the 28,492 individuals in SHARELIFE and the 7791 in ELSALIFE. The first step was to expand each dataset in order to generate for each respondent as many observations as years of age from birth to the age at the time of interview. Since SHARELIFE took place in 2008 while ELSALIFE in 2007, we dropped observations relative to 2008 in order to have a fully comparable base dataset. This results in 2,354,639 person-year observations. Table 2 reports the distribution of individuals and person-year observations by country.

The second step of the procedure involves rearranging the information generated by the job spell loops to obtain an event database, where each respondent is associated with as many observations as job episodes she/he experienced over her/his life. In other words, each row of the event database corresponds to a job spell and contains information on start and end date of the spell, job characteristics (such as wage, working hours, etc.), plus additional information on the year of retirement, unemployment and benefits. In the final step of the procedure, the base dataset is merged with the working spell dataset using

Table 2

Number of individuals and number of person-year observations by country.

\begin{tabular}{lll}
\hline Country & Number of individuals & N. of person-year observations \\
\hline Sweden & 1961 & 130,615 \\
Denmark & 2144 & 136,551 \\
Germany & 1921 & 124,020 \\
Netherlands & 2258 & 144,481 \\
Belgium & 2865 & 187,067 \\
France & 2500 & 162,095 \\
Switzerland & 1324 & 85,785 \\
Austria & 999 & 66,379 \\
Italy & 2528 & 164,870 \\
Spain & 2271 & 151,765 \\
Greece & 3092 & 197,363 \\
Poland & 1939 & 122,375 \\
Czech Republic & 1835 & 117,320 \\
Ireland & 855 & 54,426 \\
England & 7791 & 509,527 \\
Total & 36,283 & $2,354,639$ \\
\hline
\end{tabular}


the person identifier and the starting and end year of each job episode as linking variables. Reshaping the individual-level dataset into a retrospective panel, though conceptually straightforward, implies some assumptions. In particular missing data and inconsistencies especially regarding the dates at which a job spell began and finished deserves a special attention, and needs to be dealt with consistently across surveys (details in Brugiavini et al. (2013)).

\section{Cross-sectional evidence and validation}

To demonstrate the value and potential of international comparisons exploiting the full longitudinal structure of life-history data, we carry out an analysis employment at older ages using all cohorts born between 1920 and 1959 in twelve European countries ${ }^{6}$ - a sample that we could not obtain from any other employment or population surveys if we require data to be comparable across countries and present on all cohorts at all ages as they move through into retirement. Our resulting dataset contains information on job spells for each respondent from the time they left school up until 2007. We then merge in data on the public retirement age and early retirement age by country and year to provide contextual institutional data to add to our analysis.

Since our focus is on late-life employment dynamics and retirement, we select just the part of the life course trajectories from age 50 onwards, which still leaves a sample of around 440,000 person-year observations. Tables $3 \mathrm{a}$ and $3 \mathrm{~b}$ present employment rates at age 50 by country and cohort and display considerable variation, both for men (Table 3a) and particularly for women (Table 3b). Despite the fact that all these data were reported retrospectively (and for the older cohorts this would be thirty years or so in the past) the differences correspond with what one might expect: we can clearly see higher participation rates for men than for women, and the steady rise of female employment rates across cohorts, with marked differences in the level of female employment at age 50 between the southern European and northern European countries.

In order to validate the accuracy of such recall data in more detail, however, we carry out some more explicit comparisons to Labour Force Survey (LFS) data that were collected on these cohorts in previous years in two specific countries where the authors know the data well and have considerable experience in using it - England and Italy. There are two potential reasons why we might be worried about biases in the trajectories and comparisons that come from the ELSALIFE-SHARELIFE panel. Firstly, although we have excluded the very oldest cohorts in the two surveys from our analysis, the sample of individuals from the 1920 to 1929 cohort would have already been in their late seventies and early eighties at the time the retrospective data collection was carried out, and as such, will only be representative of those from this cohort that survived to these older ages, which is likely to be a selected sample of the cohort as a whole. Second, for all of the cohorts in our analysis, and particularly for the older cohorts, the post-50 employment histories that we will use for our analysis come from data that has been recalled over a period of up to thirty years so may have been recalled inaccurately.

We choose two different comparison years for our validation, 1977 and 1992- thirty years and fifteen years, respectively, before our data

\footnotetext{
${ }^{6}$ To keep our analysis relatively compact we make two different types of country selection. Firstly, we exclude the three smallest countries (in terms of sample size) from the 2007 SHARELIFE data, i.e. Ireland, Austria and Switzerland. Second, as we are interested in labour supply as a choice, we want to exclude individuals who may have been exposed to mandatory work programs at some point in their life-history. Hence, we exclude all individuals in the former Eastern European countries (including the former East Germany) and only keep individuals in any other countries where we are sure from the residence history that more than half of their working life pre-1989 was spent in Western countries. This results in a final analysis sample of 27,427 individuals and $1,785,103$ person year observations.
}

Table 3a

Probability of working at age 50, by date of birth cohort and country: Male.

\begin{tabular}{llllll}
\hline & $1920-29$ & $1930-39$ & $1940-49$ & $1950-59$ & Delta \\
\hline England & 0.980 & 0.954 & 0.929 & 0.902 & -0.08 \\
Sweden & 0.964 & 0.972 & 0.957 & 0.964 & 0.00 \\
Denmark & 0.954 & 0.953 & 0.935 & 0.916 & -0.04 \\
Belgium & 0.952 & 0.939 & 0.921 & 0.900 & -0.05 \\
Spain & 0.951 & 0.928 & 0.915 & 0.873 & -0.08 \\
Germany & 0.929 & 0.973 & 0.930 & 0.837 & -0.09 \\
Greece & 0.921 & 0.880 & 0.912 & 0.936 & 0.02 \\
Netherlands & 0.879 & 0.936 & 0.913 & 0.905 & 0.03 \\
Italy & 0.876 & 0.930 & 0.885 & 0.938 & 0.06 \\
France & 0.854 & 0.929 & 0.913 & 0.890 & 0.04 \\
\hline
\end{tabular}

Note: Authors calculations SHARELIFE-ELSALIFE. Final column 'Delta' presents the difference between the 1920-29 and 1950-59 cohorts for each country.

Table 3b

Probability of working at age 50, by date of birth cohort and country: Female.

\begin{tabular}{llllll}
\hline & $1920-29$ & $1930-39$ & $1940-49$ & $1950-59$ & Delta \\
\hline Sweden & 0.754 & 0.881 & 0.911 & 0.893 & 0.14 \\
England & 0.689 & 0.766 & 0.805 & 0.821 & 0.13 \\
Denmark & 0.641 & 0.799 & 0.843 & 0.889 & 0.25 \\
Germany & 0.547 & 0.607 & 0.637 & 0.709 & 0.16 \\
France & 0.522 & 0.554 & 0.704 & 0.799 & 0.28 \\
Netherlands & 0.308 & 0.353 & 0.519 & 0.660 & 0.35 \\
Belgium & 0.294 & 0.383 & 0.540 & 0.691 & 0.40 \\
Greece & 0.288 & 0.375 & 0.369 & 0.420 & 0.13 \\
Spain & 0.257 & 0.251 & 0.303 & 0.511 & 0.25 \\
Italy & 0.248 & 0.328 & 0.388 & 0.497 & 0.25 \\
\hline
\end{tabular}

Note: Authors calculations SHARELIFE-ELSALIFE. Final column 'Delta' presents the difference between the 1920-29 and 1950-59 cohorts for each country.

collection took place. In each of these years we have a highly trusted measure of the true cross-sectional age profile of employment rates from the national Labour Force Surveys that were collected at the time. From this data we can plot the proportion of each single year-of-birth cohort that was working and compare that proportion to the fraction of those in our ELSALIFE-SHARELIFE sample who, when interviewed subsequently in 2006/2008 reported that they were in paid work 1977 and $1992 .^{7}$

These comparisons, for England and Italy, and for men and women separately are plotted in Fig. 1 (1977) and Fig. 2 (1992). Whilst the data from ELSALIFE and SHARELIFE-Italy are noisier, as might be expected given the smaller numbers of respondents in each of the single year-ofbirth cohorts (particularly for Italy), the patterns of employment rates across cohorts are strikingly similar in comparison to those that were measured at the time. Fig. 1a shows the high and stable pattern of employment rates across cohorts for men, with the cross-country differences in participation rates for the youngest cohorts (who were in their late teens and early twenties in 1977) clearly apparent in the ELSALIFE and SHARELIFE data. Fig. 1b shows that the profiles for women do not match quite as closely but still show a good correspondence and reproduce the general shape of the profile across cohorts within each country, and the key differences between countries.

Figs. 2a and $2 \mathrm{~b}$ contain the comparisons for 1992, which covers the latter part of the working lifecycle (ages 33-72 for the cohorts born

\footnotetext{
${ }^{7}$ These validations and comparisons are not the main purpose of the paper so the exercise we carry out here is relatively crude. Specifically, the precise age on the date of interview, and the time period of assessment over which the LFS was carried out, will vary across observations within the LFS samples in each survey year. This could be taken into account to generate an even more accurate control total, but is unlikely to make any substantive difference to our conclusions here, and is left as a topic for future research, perhaps in combination with replicating our comparisons on a more formal basis for all countries in the ELSA-SHARE sample.
} 

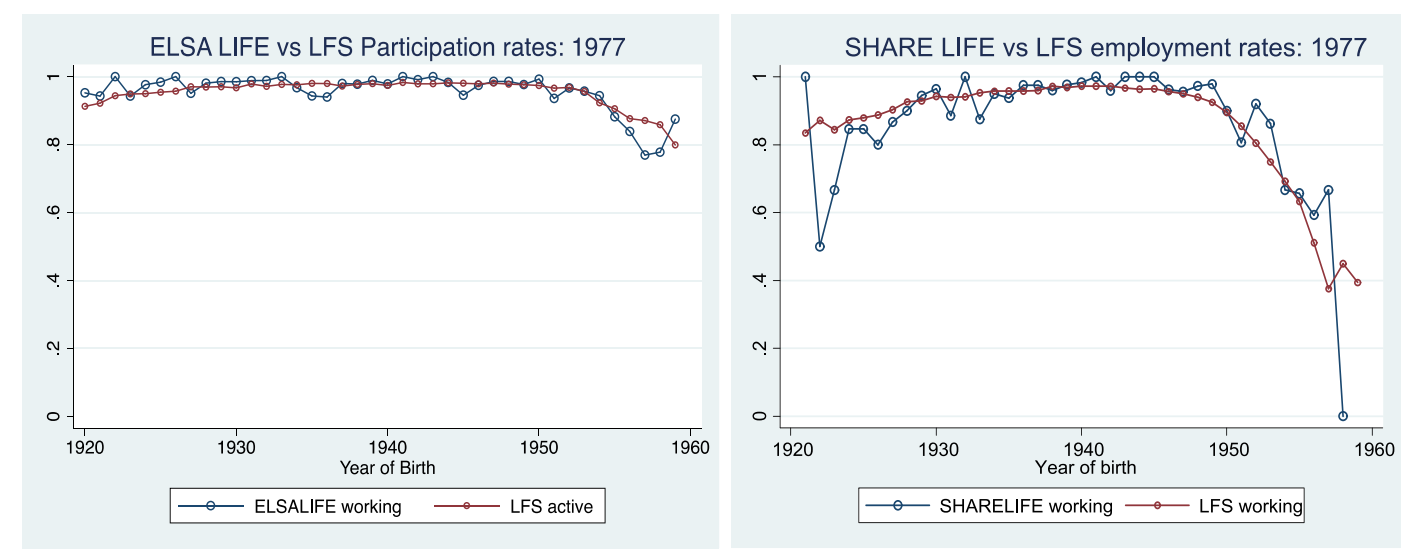

Fig. 1a. Male cohort employment patterns, ELSA and SHARE-ITALY versus LFS, 1977.
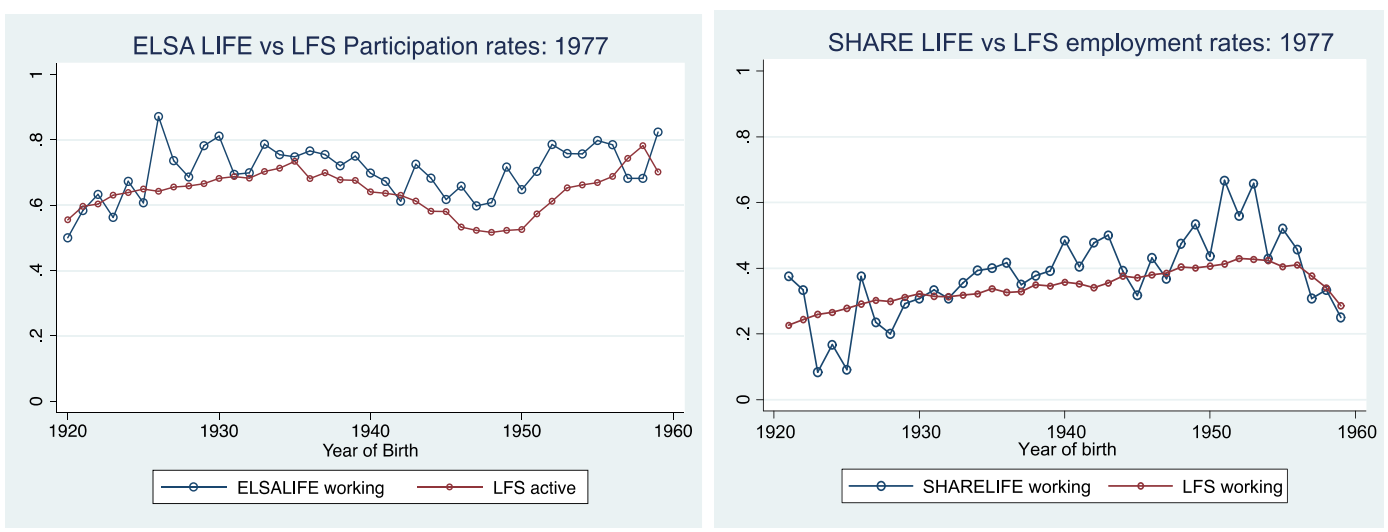

Fig. 1b. Female cohort employment patterns, ELSA and SHARE-ITALY versus LFS, 1977.
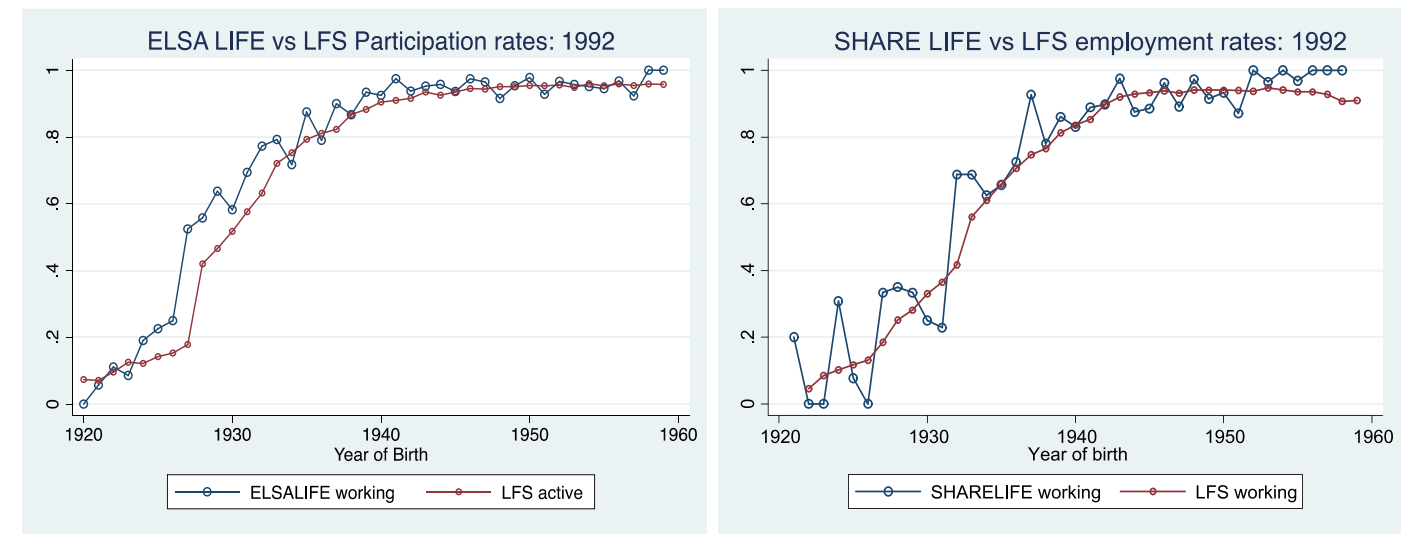

Fig. 2a. Male cohort employment patterns, ELSA and SHARE-ITALY versus LFS, 1992.

between 1920 and 1959). Once again, the patterns that were observed at the time in the 1992 LFS data in each country are well mirrored in the ELSALIFE and SHARELIFE data, with the caveat that there is more noise in the latter profiles due to the much smaller sample sizes. The lower participation rates of older cohorts, who had already retired in considerable numbers by 1992, is matched well in all four comparisons, and the differences in levels and shapes of the cohort profiles across countries is remarkably similar across the two different sources of data.

One final point from these comparisons relates to the degree to which they provide evidence on potentially non-random survival into the life-history interview and hence a differentially selected sample when we use LH data to compare across cohorts, as we will do in what follows. Figs. 2a and 2b suggest that the ELSALIFE sample reports higher rates of participation in 1992 for the cohorts born before around 1935, in comparison to that which was measured in the LFS at the time. Differential mortality is one potential, and likely, explanation for this such a phenomenon might be expected if those who are healthier than average and typically with better economic circumstances were more likely to survive to age seventy and over. The fact that this difference does not show itself in the Italian cohorts of the same age is not 

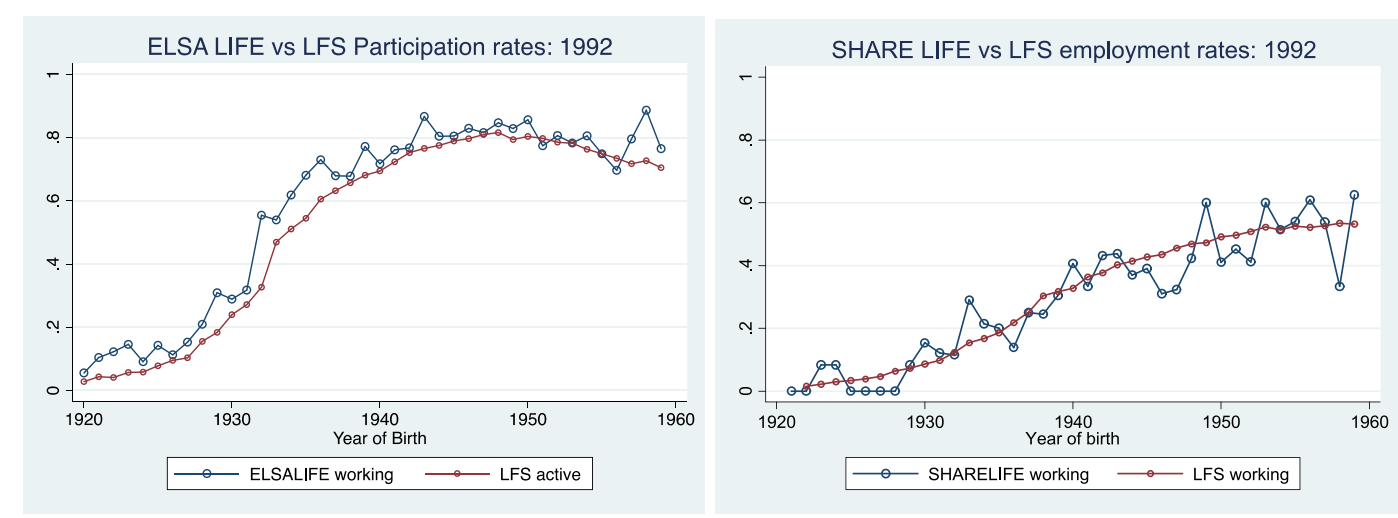

Fig. 2b. Female cohort employment patterns, ELSA and SHARE-ITALY versus LFS, 1992.

necessarily evidence of the absence of a similar effect in the Italian data - if work at older ages was not correlated with life-course health and SES factors to the same extent (due, for example, to the design of retirement and pension benefits which were considerably different between the two countries at that time) then such a selection effect would not be apparent in data on employment rates. But even if such selection effects related to differential mortality are present, we can use comparisons such as these to help us understand how any biases might affect qualitative conclusions that might be drawn from subsequent analysis. In this specific case, we can say that comparisons of lifetime labour market activity across cohorts are likely to understate any increase in work that has occurred for more recent cohorts in comparison to their predecessors.

An alternative way to validate the LH data on employment trajectories is to consider whether the reported trajectories correlate with other factors in a way that is consistent with what is known from previous studies using alternative sources of data and methods of identification. Whilst there are many possibilities here, for our purposes we choose to look at the correlation of employment at older ages and retirement ages in public pension systems - a correlation that has been robustly documented using international comparisons in Gruber and Wise $(1999,2004)$ and in several follow-up studies. Gruber and Wise $(1999,2004)$ use cross-sectional microdata from a number of OECD countries, combined with microsimulation of pension rules and arrangements in each country, to estimate the correlation between employment at older ages and the implicit tax on work that arises from the structure of the pension system and retirement ages. This relationship is consistently shown to be strong for men but is often not estimated for women or, if it is estimated, is found to be statistically weaker. While we do not calculate the same implicit tax rates effects, we simply note that a key issue in driving variation in implicit tax rates is the 'eligibility age' for public pensions and hence we would expect to see a positive

Table 4

Estimated effect of being under public retirement age on likelihood of being in paid work.

\begin{tabular}{llll}
\hline All aged 50-74 & & & \\
\hline & All & Male & Female \\
\hline Coefficient & $\mathbf{0 . 0 4 8}$ & $\mathbf{0 . 0 7 0}$ & $-\mathbf{0 . 0 0 2}$ \\
Standard error & 0.015 & 0.020 & 0.014 \\
Gender fixed effects & $\mathrm{Y}$ & $\mathrm{N}$ & $\mathrm{N}$ \\
Age fixed effects & $\mathrm{Y}$ & $\mathrm{Y}$ & $\mathrm{Y}$ \\
5-year cohort fixed effects & $\mathrm{Y}$ & $\mathrm{Y}$ & $\mathrm{Y}$ \\
Country fixed effects & $\mathrm{Y}$ & $\mathrm{Y}$ & $\mathrm{Y}$ \\
N cohort-country-age cells & 2600 & 1300 & 1300 \\
N underlying person-year obs & 409,980 & 188,295 & 221,685 \\
\hline
\end{tabular}

correlation between whether people are working and whether they are under the state retirement age.

To carry out such an analysis we select all the person-years of data from the ELSALIFE SHARELIFE sample where individuals in the 1920-1959 birth cohorts were aged between 50 and 74 and treat this dataset as a pooled sample, covering multiple countries, ages and cohorts/years. We then aggregate the data to the country-cohort-year cell level and run a simple ordinary least squares model of the proportion working on the proportion of the group who are below the state retirement age for their particular birth-cohort in that country in that year. In order to capture other unobserved determinants of retirement and employment probabilities we include a complete set of fixed effects to capture single years of age, country, five-year birth cohorts, and gender. As with the Alessie et al. (2013) paper on the public pension wealth and financial assets, the key identification of effects in this model comes from historical and geographical variation in the pension systems faced by the various ELSALIFE-SHARELIFE cohorts. Table 4 presents the results of this analysis and shows that this positive correlation does indeed emerge in the ELSALIFE-SHARELIFE data. That is to say, public pension ages are strongly positively correlated with the probability of work even when controlling for the many other factors that are captured by our fixed effects, and this overall correlation is driven by a strong correlation for men, since we find no statistically significant correlation for women.

\section{Late-life employment trajectories around Europe}

With the cross-sectional patterns in employment at older ages validated, both in terms of their correspondence with other data collected at the time the cohorts were working, and in terms of their correlations with contextual variables capturing labour market incentives, we can move on to illustrating the added value of having the life-history trajectory of employment for the LH cohorts and analyzing this as panel data in its own right. We begin by a simple adaptation to our previous regression analysis that illustrates the power of the longitudinal data. Tables 3a and 3b showed cohort and country differences in the proportions of individuals, and particularly women, who were working at age 50 - the age at which our retirement 'trajectories' begin. When treating the data as pooled cross-sections in our analysis of Table 4 we were implicitly ignoring the significance of this aspect of the variation in our data for the profiles beyond age 50 . That is to say that the labour market outcome for a 60 -year old, for example, was not conditioned on whether or not that 60-year old had previously been working at age 50 . This is a consequence of the cross-sectional approach to data analysis and also a necessary assumption of the previous Gruber-Wise type analysis which was limited by only having pooled time series of crosssectional surveys available on a comparable basis across countries.

In Table 5 we repeat our previous empirical analysis from Table 4 
Table 5

Estimated effect of being under public retirement age on likelihood of being in paid work.

All aged 50-74 who were working at age 50

\begin{tabular}{llll}
\hline & All & Male & Female \\
\hline Coefficient & $\mathbf{0 . 1 2 6}$ & $\mathbf{0 . 0 9 6}$ & $\mathbf{0 . 1 0 3}$ \\
Standard error & 0.009 & 0.020 & 0.012 \\
Gender fixed effects & $\mathrm{Y}$ & $\mathrm{N}$ & $\mathrm{N}$ \\
Age fixed effects & $\mathrm{Y}$ & $\mathrm{Y}$ & $\mathrm{Y}$ \\
5-year cohort fixed effects & $\mathrm{Y}$ & $\mathrm{Y}$ & $\mathrm{Y}$ \\
Country fixed effects & $\mathrm{Y}$ & $\mathrm{Y}$ & $\mathrm{Y}$ \\
N cohort-country-age cells & 2600 & 1300 & 1300 \\
N underlying person-year obs & 302,203 & 175,710 & 126,493 \\
\hline
\end{tabular}

but now using just the sample of respondents whose trajectories indicated that they were working at age $50 .^{8}$ The effects of the state pension age on employment are actually larger and more precisely estimated once we look only at the individuals who were in the labor market at aged 50 and hence truly at risk of being affected by state retirement ages. More interestingly, and importantly, however, the differences between men and women disappear. Hence the previous finding of a differential effect of state pension ages on employment at older ages for men and women can be seen to be due to the fact that fewer women are in the labour market in the first place - for those women who are working at age 50, the state pension rules have similar effects to those it has for men. ${ }^{9}$

With full life-history trajectories for employment we can also go beyond a single year measure of employment at each age and consider the total number of years worked after age 50. Table 6 shows the variation in this total amount of work post- 50 by country and cohort, for all males and females who were actually working when they were age 50, and again reveals striking variation. Looking at the 1920-29 and 1930-39 cohorts, there is a difference of almost four years of total labour supply after age 50 across the different European countries in our sample, with those in the older cohort in Scandinavian countries working for almost fifteen years and those in France or Belgium having worked for around eleven. Fig. 3 presents a scatter plot of the average years worked post-50 in each cohort-country-gender cell against the corresponding public retirement age for that cohort, and shows the strong positive relationships between the two, both for all older adults and for just the sample that reports working at age 50, suggestive of an important relationship between state retirement ages and the total amount of work at older ages that a cohort supplies to the labour market.

Looking at the younger cohorts in Table 6, however, it is

\footnotetext{
${ }^{8}$ Of course, we could go further and estimate a dynamic labour supply model at all ages, or construct a measure of life-cycle labour market attachment and interact such a variable with the pension age indicators to investigate the effects of labour market attachment on retirement behaviour and the effectiveness of retirement incentives in detail. Whilst this is an interesting topic for future research, our intention here is simply to consider how our previous estimates are affected by using the work trajectory data to control for whether or not the worker was in the labour market at all at age 50 .

${ }^{9}$ Further investigation suggests the full life history is required to understand these effects correctly. If we run the same models simply on the sample that have 'ever worked' which is a control that is sometimes available in standard labour market surveys we do find statistically significant effects for women (in contrast to our estimates in Table 4) but they are still only half the magnitude of the male effects, presumably because there is a large fraction of women who worked before childbirth but did not subsequently return. More specifically, we find a coefficient of 0.076 for men (standard error 0.019 ) and only 0.030 for women (standard error 0.0143) and consequently the coefficient for all individuals is also lower than it's corresponding value in Table 5 at 0.049 (standard error 0.013))
}

Table 6

Number of years worked post 50, if working at 50, by country and year of birth.

\begin{tabular}{lllll}
\hline & $1920-1929$ & $1930-1939$ & $1940-1949$ & $1950-1959$ \\
\hline Sweden & 14.8 & 13.7 & 11.9 & 5.6 \\
Denmark & 14.5 & 12.8 & 10.9 & 4.5 \\
Spain & 14.0 & 12.7 & 10.7 & 4.8 \\
England & 13.9 & 12.8 & 10.4 & 4.8 \\
Greece & 13.3 & 12.4 & 10.3 & 5.1 \\
Germany & 12.9 & 11.1 & 10.1 & 5.2 \\
Italy & 12.1 & 10.4 & 8.3 & 4.5 \\
Netherlands & 11.9 & 10.5 & 10.1 & 5.0 \\
Belgium & 11.1 & 9.7 & 8.9 & 4.7 \\
France & 10.9 & 9.9 & 9.1 & 4.7
\end{tabular}

Note: Since data collection was in 2007/8 some members of 1950-1959 cohort had yet to reach age 50 at time of measurement (see discussion in main text on censoring effects in this outcome).

immediately apparent that there is far less variation across countries in the years worked post-50 for these cohorts than for their predecessors. This is indicative of a broader issue with such a measure, namely that the younger cohorts have not yet completed their full labour market trajectories so their data are right-censored. Indeed, the youngest cohort of our sample was only in its early fifties at the time the data were collected (and the very youngest members of this cohort had yet to even reach age 50) so this censoring effect is extreme. Hence, any differences between countries, or between these cohorts and their predecessors are yet to emerge. Yet, one of the key questions in ageing policy research relates to how much we might expect current cohorts of older workers to work in comparison to their predecessors. In this case the LH data has provided previously unknown information on the full trajectories of older cohorts but has not (yet) provided the comparison data on younger cohorts.

There are a number of solutions to this that could be explored in further research. One natural extension to what we do here would be to link the LH respondents to the subsequent ten years of panel data in the main ELSA and SHARE surveys that have occurred since the ELSALIFE and SHARELIFE instruments were fielded, in order to see the next part of the employment trajectory for the younger cohorts. Alternatively, one could carry out a more complex statistical analysis of the ELSALIFE SHARELIFE data and run a duration model for time spent in the labour market that allows for censoring in the data processes and estimates differences between cohorts in the duration of employment post-50. Since our purpose in this paper is more to stimulate interest in internationally comparable LH data and illustrate the potential of such data, we leave these two extensions to future research and instead content ourselves with some graphical analysis of the trajectories that is sufficient to show key differences emerging between the full employment trajectories for each cohort.

In the final set of figures in this section, we plot the evolving trajectory for each five-year cohort as the respondents age. Fig. 4a shows the average number of years worked post-50 in Italy and England by cohort. At early ages, many of the cohort members are working so the average number of years worked post-50 rises steeply. As cohort members begin to exit the labour force the curve begins to flatten and gradually asymptotes towards the permanent level that it would take if no-one were working anymore. As is clear from the figure, the full trajectories are only observed for the oldest (1920-1924) cohort, but differences in the asymptotic value of the trajectory are clear, particularly in Italy, where younger cohorts have been working 'less' than their older predecessors. For the youngest cohorts, smaller fractions of the trajectory have been observed to date (suggesting duration analysis would have limited statistical power) but what fractions of trajectories do exist suggest only small differences, if any, across cohorts. Fig. 4b shows the corresponding trajectories for the set of men who were observed working at age 50 and, whilst the cohort differences are similar and certainly larger in Italy than they are in England - the levels of 

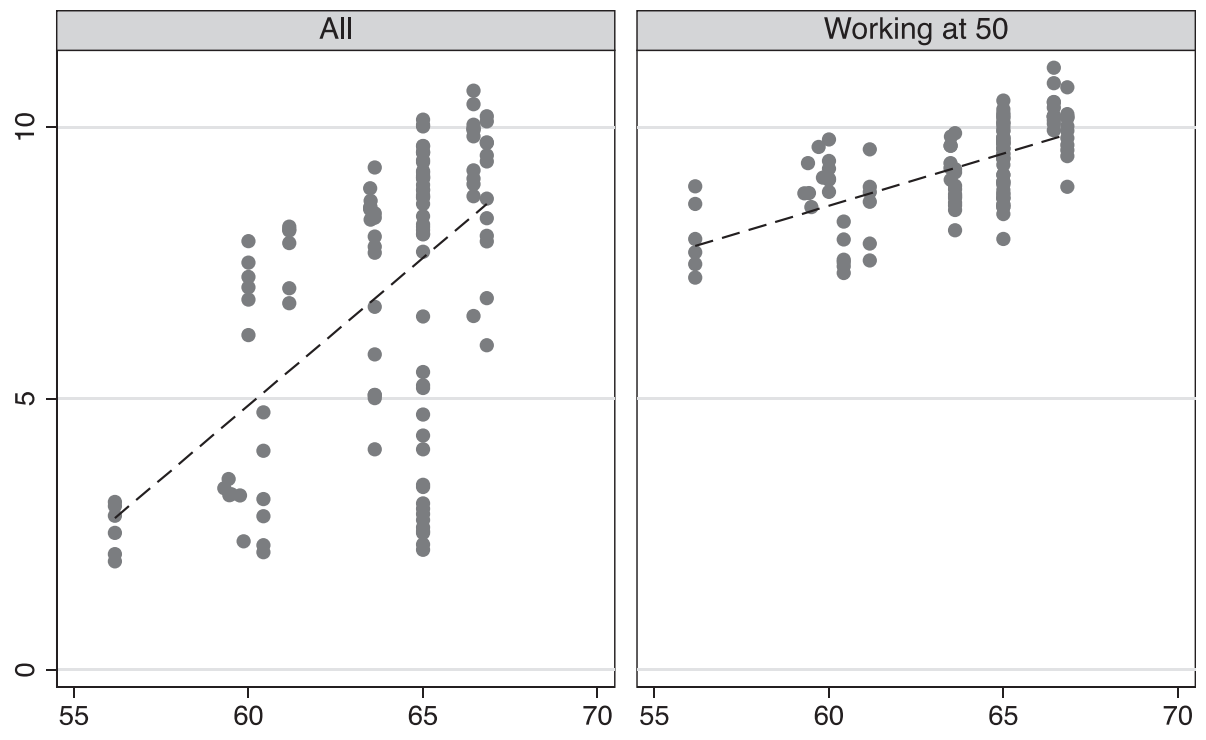

Public Retirement Age

- Country-Cohort cell data - - - - Fitted values

Fig. 3. Retirement ages and years worked post-50, by country, sex and 5-year date of birth cohort.
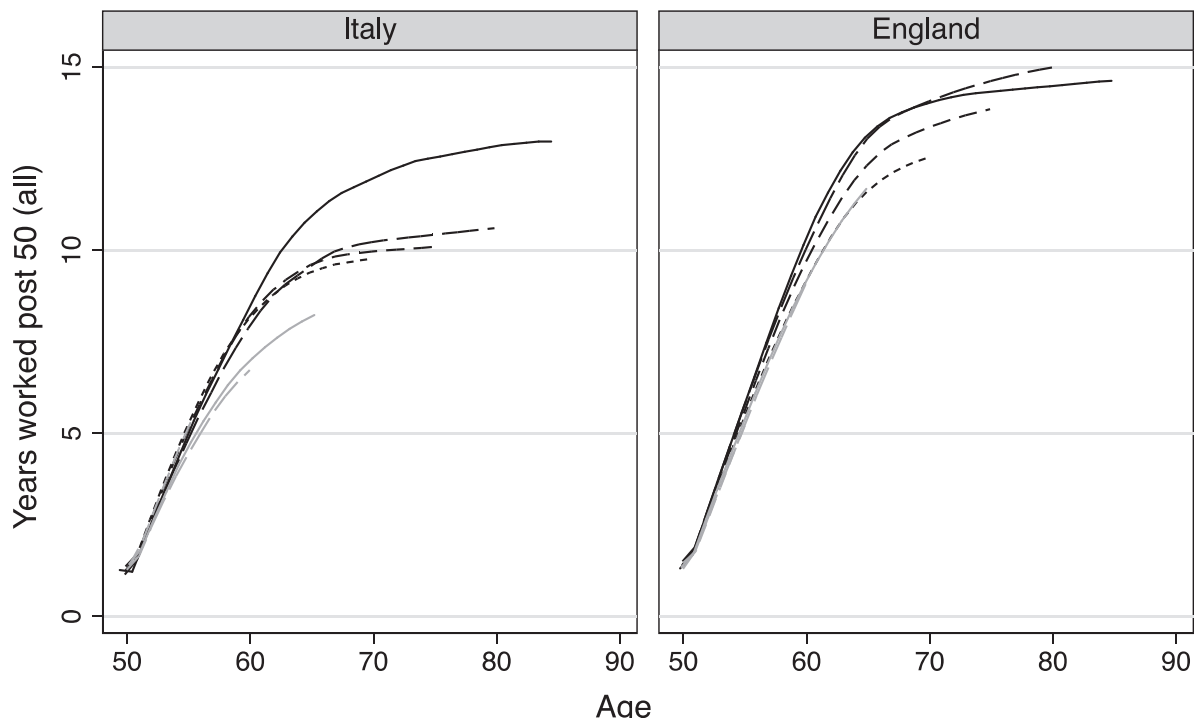

Age

$\begin{aligned} 1920 & ---1925 & -----1930 & \ldots \ldots-\ldots & 1935 \\ 1940 & ---1945 & -----1950 & \ldots \ldots-\ldots & 1955\end{aligned}$

Fig. 4a. Years worked post 50 in England and Italy, by cohort: Male.

years worked are comparable between the two countries, suggesting much of the difference in late-life labour supply was in fact due to preexisting differences in labour market participation prior to age $50 .{ }^{10}$

Figs. 5a and 5b shows the corresponding trajectory analysis for women where the differences are more striking. Firstly, one can see large differences between the total late-life labour market participation of women in Italy and in England, with the English working eight years

\footnotetext{
${ }^{10}$ The 1920 cohort in Italy, conditional on working age 50, seem to work substantially more than any other cohort. Most likely the reason is that younger cohorts had the opportunity to take early retirement, which older cohorts could not.
}

on average after age 50, compared to three in Italy. Unlike for the men, the cohort effects in Fig. 5a, however, show clearly that each cohort is working more than its predecessor. Once again, however, this is a pattern that is driven by labour market participation before age 50 , as opposed to changes in the evolution of trajectories for those who are working at age 50. The latter trajectories, presented in Fig. 5b, show the similar cohort effects to those observed for men in Fig. 4b, and indeed once again the levels of subsequent late-life labour market participation are more similar across countries in this case.

Taking this type of analysis further, and extending it to more countries, our final piece of evidence moves away from just looking at the number of years of work individuals have undertaken after aged 50 and looks instead at the number of jobs that they have held. The 


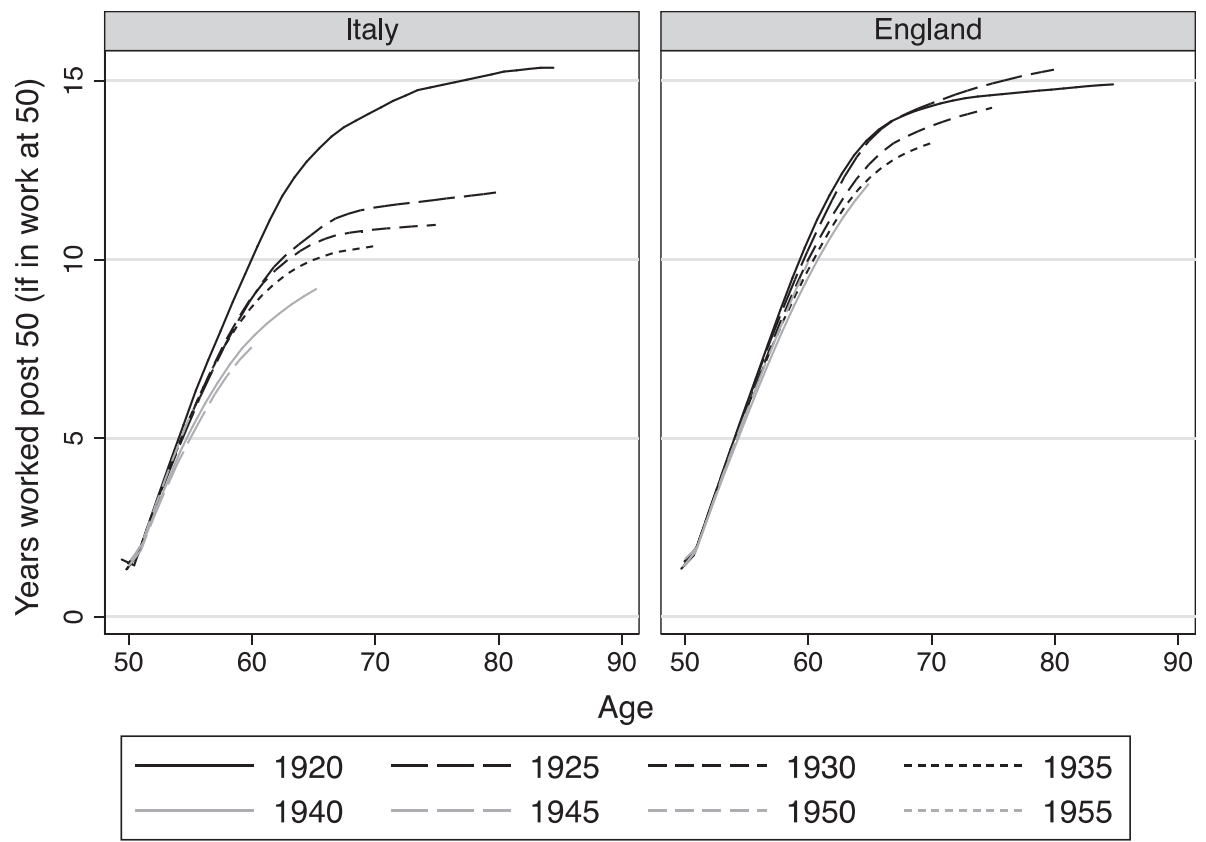

Fig. 4b. Years worked post 50 in England and Italy if working at 50, by cohort: Male.

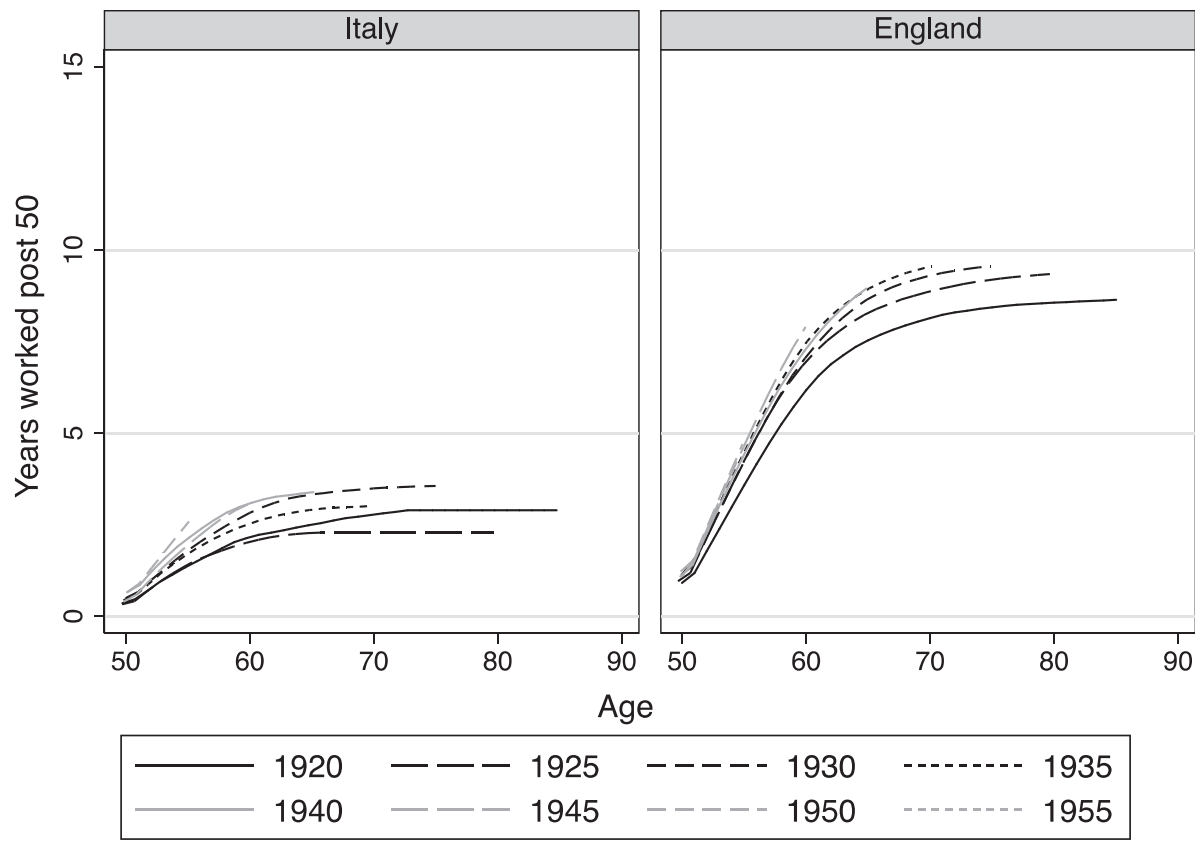

Fig. 5a. Years worked post 50 in England and Italy, by cohort: Female.

potentially changing flexibility of the labour market for older workers of more recent cohorts has become a topic of some importance for policymakers and these trajectory data offer the chance to get a unique insight into this question. Specifically, we can see the extent to which differences in the late-life labour supply, whether across cohorts or across countries, has come through individuals just staying in their jobs for less (or more) time, or through job to job transitions and the use of a more (or less) flexible labour market. Fig. 6 uses the same methodology as above but plots the average number of jobs in the cohort trajectories for nine of our countries. If all members stayed in the same job that they held at age 50 until they retired, this trajectory would be flat and take the value one throughout.
Once again, the differences across countries and across cohorts are striking. Some countries (England, Sweden and Denmark) have always had higher rates of job mobility at older ages, but two of these - Sweden and England- are also the countries where recent cohorts of older workers in England are considerably more likely to change jobs after age 50 than their predecessors. Whilst early cohorts in Germany and France had rather low levels of mobility, recent cohorts are also looking rather different to their predecessors. Indeed there are a number of countries (Germany, Spain, Denmark) where the cohort effects are rather discreet and likely to be a specific function of changes in labour market institutions such as changes in retirement ages or minimum or maximum tenure in jobs. Yet some other European countries show very 


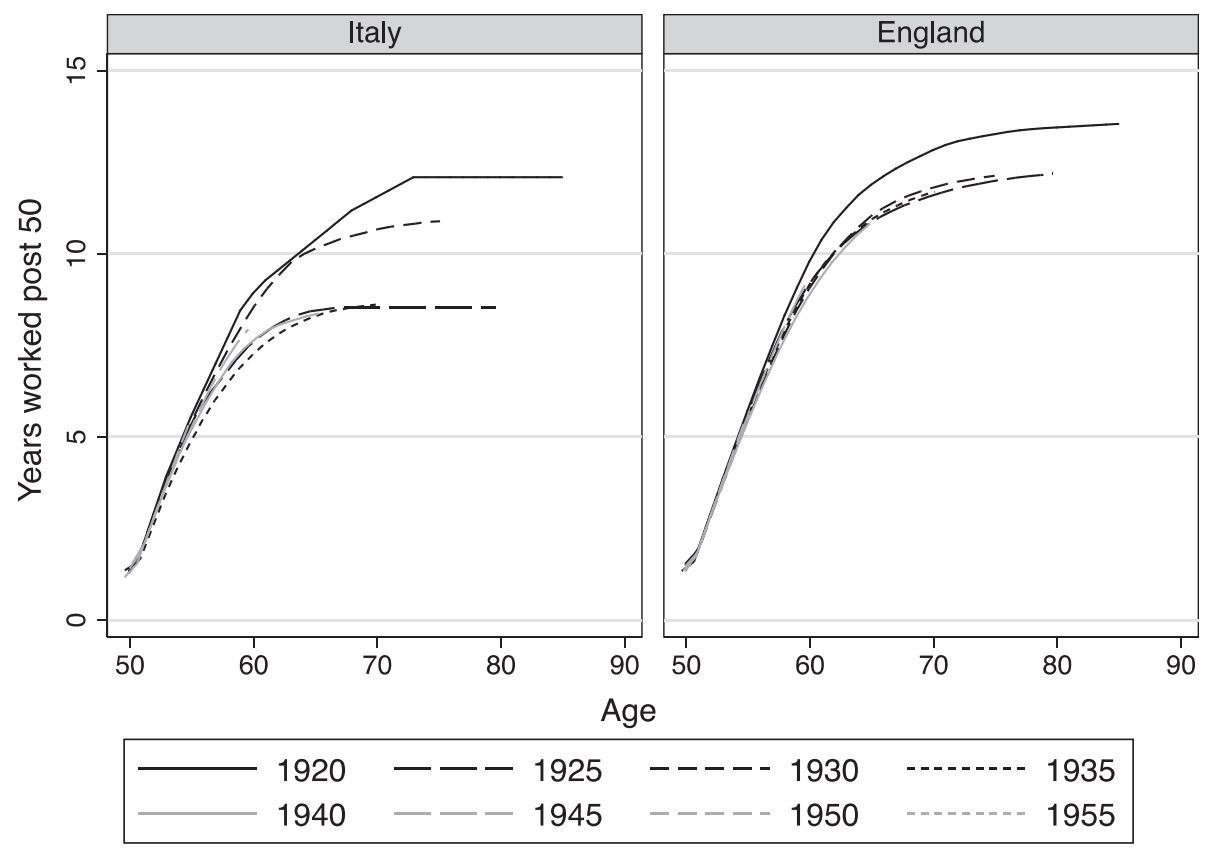

Fig. 5b. Years worked post 50 in England and Italy if working at 50, by cohort: Female.
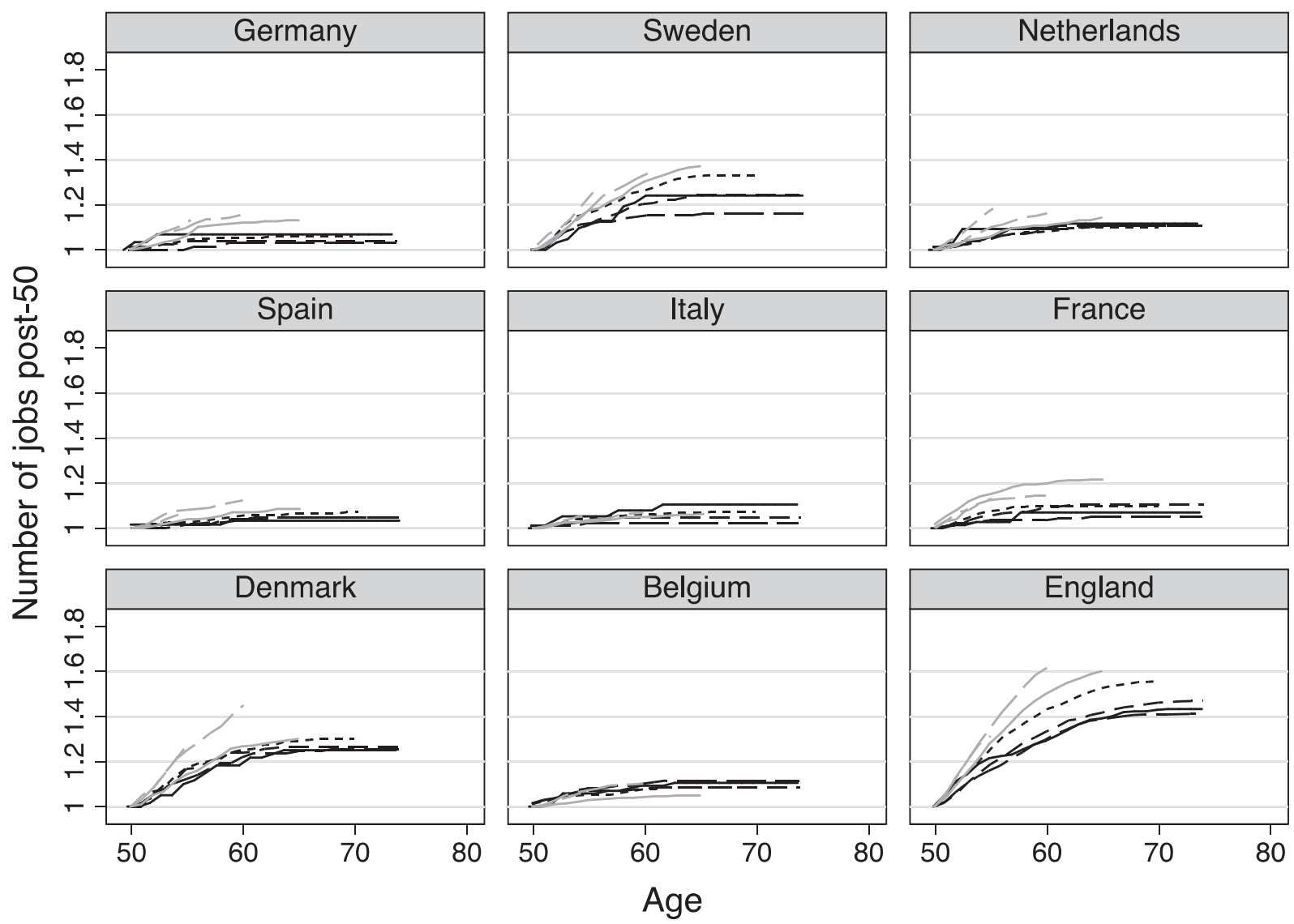

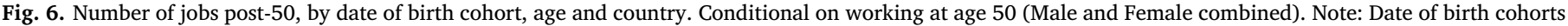
indicated as described in legend to Figs. 4 and 5.

different patterns, with Italy, Spain, Greece and Belgium, amongst others, having very low rates of job mobility albeit with different changes across cohorts.
In general, however, Fig. 6 shows that, when we do see evidence of cohort effects, it tends to be that younger cohorts are now having more jobs, and hence more labour market mobility at older ages than their 
predecessors. Recalling our brief discussion of potential selection biases in the retrospective sample, if members of our oldest cohorts are a disproportionally advantaged subsample of the original birth cohort then in fact this increase will be an understatement of true lifetime differences between the cohorts.

\section{Conclusions}

This paper has documented the clear benefits to researchers in the economics of ageing of using internationally comparative data drawn from retrospectively collected life-histories. Advances in survey methods, and an enhanced understanding of how to design questions that allow respondents to most reliably recall information from their past, have made such data collection activities more robust and they are now being used to considerable effect in ageing studies around the world. Indeed, for some longitudinal studies (for example SHARE) it is the life-history component of the data collection that has yielded the greatest number of high impact scientific papers and this trend will likely continue.

There are questions surrounding the quality and representativeness of LH data, as with all types of quantitative data. In this case these issues relate to the accuracy of recalled responses and possible biases in the sample that are created by observing the entire trajectory at one time, which could be non-negligible in cohorts where LH data are collected at very old ages. We have documented some of what is known about these issues but would argue that more work can be done in these dimensions. Once researchers know more about the pros and cons of working with LH data they can choose the kinds of situations and applications where such data have a comparative or absolute advantage in comparison to other sorts of data and methods. And as more is known along those lines, it is likely that there will be also be more learning around best practice and how questions in LH studies can be best designed, and such an agenda should be encouraged given the considerable analytical potential of the resulting data. With continued improvements in data collection methods could come other applications and benefits - LH data would, for example, provide the ultimate baseline for all new entrants to longitudinal studies and could also be used to collect summary information on a one-off basis on key satellite individuals related to sample members, such as their parents, siblings, children or even neighbours.

Finally, one area where the benefits of LH data are only recently becoming apparent is in the degree to which they facilitate a full dynamic trajectory analysis using panel data longitudinal methods, as opposed to a more straightforward empirical design, which summarises earlier life exposures and looks for consequences on late-life outcomes. Whilst the latter type of application accounted for most of the early papers using LH data in the ageing studies, recent work is beginning to exploit the full dynamics of the trajectory on a more comprehensive basis. We have pointed to some key studies in this respect, but also given a new application in the area of labour market trajectories where we think there is considerable promise in further research. In particular we have shown large differences in the degree to which the total amount of late-life work in the paid labour market has been changing across cohorts in Europe and also differences in the way that labour market flexibility has been evolving for older workers.

Whilst our example of this dynamic analysis of LH data related to labour market trajectories but there are many other types of process that could be investigated with such methods. Female employment histories and their links to household formation and childbearing are another. Links between work and residential mobility, or household formation, housing and subsequent links to health and economic outcomes are also particularly promising possibilities.

\section{Acknowledgements}

This paper was originally presented at the work was presented at the Gateway to Global Aging Data Research Conference, funded by the National Institute on Aging (2R01 AG030153). Thanks are due to participants at the conference as well as to the editor and referees for useful comments, and particularly to Peter Spittal (UCL) and Raluca Elena Buia (Venice) for invaluable research assistance in preparing the datasets used in this analysis. Banks is grateful for funding from the ESRC Centre for Microeconomic Analysis of Public Policy at IFS. This paper uses data from the generated Job Episodes Panel (DOI: 10.6103/ SHARE.jep.600), see Brugiavini et al. (2013) and Antonova (2014) for methodological details. The Job Episodes Panel release 6.0.0 is based on SHARE Waves 1, 2 and 3 (SHARELIFE) (DOIs: 10.6103/ SHARE.w1.611, 10.6103/SHARE.w2.611, 10.6103/SHARE.w3.611). The SHARE data collection has been primarily funded by the European Commission through FP5 (QLK6-CT-2001-00360), FP6 (SHARE-I3: RIICT-2006-062193, COMPARE: CIT5-CT-2005-028857, SHARELIFE: CIT4-CT-2006-028812) and FP7 (SHARE-PREP: N ${ }^{\circ} 211909$, SHARELEAP: $\mathrm{N}^{\circ} 227822$, SHARE M4: $\mathrm{N}^{\circ} 261982$ ). Additional funding from the German Ministry of Education and Research, the Max Planck Society for the Advancement of Science, the U.S. National Institute on Aging (U01_AG09740-13S2, P01_AG005842, P01_AG08291, P30_AG12815, R21_AG025169, Y1-AG-4553-01, IAG_BSR06-11, OGHA_04-064, HHSN271201300071C) and from various national funding sources is gratefully acknowledged (see www.share-project.org). Data from the English Longitudinal Study of Ageing (ELSA) were made available by the UK Data Service. ELSA was developed by a team of researchers based at University College London, University of Manchester, the Institute for Fiscal Studies and the National Centre for Social Research, with funding provided by the US National Institute of Aging, and a consortium of UK government departments. http://doi.org/10.5255/ UKDA-SN-5050-15.

\section{References}

Alessie, R., Angelini, V., van Santen, P., 2013. Pension wealth and household savings in Europe: evidence from SHARELIFE. Eur. Econ. Rev. 63, 308-328.

Antonova, L., Aranda, L., Pasini, G., Trevisan, E., 2014. Migration, family history and pension: the second release of the SHARE Job Episodes Panel. SHARE Working Paper Series, 18.

Arpino, B., Gumà, J., Julià, A., 2018. Family histories and the demography of grandparenthood. Demographic Res. 39, 1105-1150.

Attanasio, O., Brugiavini, A., Trevisan, E., Weber, G., 2014. The consequences of financial hardship (and recessions) on income and welfare. In: Brugiavini, A., Weber, G. (Eds.), Longer-Term Consequences of the Great Recession on the Lives of Europeans. Oxford University Press, Oxford.

Avendano, M., Berkman, L.F., Brugiavini, A., Pasini, G., 2015. The long-run effect of maternity leave benefits on mental health: evidence from European countries. Soc. Sci. Med. 132, 45-53.

Banks, J., Kelly, E., Smith, J.P., 2013. Spousal health effects: the role of selection. In: Discoveries in the Economics of Aging. University of Chicago Press, pp. 255-279.

Banks, J., Kesternich, I., Smith, J.P., 2018. International Differences in Interspousal Health Correlations.

Banks, J., Smith, J.P., 2012. International comparisons in health economics: evidence from aging studies. Annu. Rev. Econ. 4, 57-81. https://doi.org/10.1146/annureveconomics-080511-110944.

Belli, R.F., 1998. The structure of autobiographical memory and the event history calendar: potential improvements in the quality of retrospective reports in surveys. Memory 6 (4), 383-406.

Belli, R.F., Shay, W.L., Stafford, F.P., 2001. Event history calendars and question list surveys: a direct comparison of interviewing methods. Public Opin. Q. 65 (1), 45-74.

Bharadwaj, P., Zivin, J.G., Mullins, J.T., Neidell, M., 2016. Early-life exposure to the great smog of 1952 and the development of asthma. Am. J. Respir. Crit. Care Med. 194 (12), 1475-1482.

Bingley, P., Martinello, A., 2017. Measurement error in income and schooling and the bias of linear estimators. J. Labor Econ. 35 (4), 1117-1148.

Blane, D., 2005. Cohort profile: the Boyd Orr lifegrid sub-sample-medical sociology study of life course influences on early old age. Int. J. Epidemiol. 34 (4), 750-754.

Brown, M., 2013. Assessing recall of early life circumstances: evidence from the National Child Development Study. Longitudinal Life Course Stud. 5 (1), 64-78. 
Brugiavini, A., Cavapozzi, D., Pasini, G., Trevisan, E., 2013. Working life histories from SHARELIFE: a retrospective panel SHARE WP Series, pp. 11-13.

Gruber, J., Wise, D., 1999. Social Security Programs and Retirement around the World. University of Chicago Press.

Gruber, J., Wise, D., 2004. Social Security Programs and Retirement around the World: Micro-Estimation. The University of Chicago Press.

Havari, E., Mazzonna, F., 2015. Can we trust older people's statements on their childhood circumstances? Evidence from SHARELIFE. Eur. J. Popul. 31 (3), 233-257.

Havari, E., Peracchi, F., 2017. Growing up in wartime: evidence from the era of two world wars. Econ. Human Biol. 25, 9-32.

Kesternich, I., Siflinger, B., Smith, J.P., Winter, J.K., 2014. The effects of World War II on economic and health outcomes across Europe. Rev. Econ. Stat. 96 (1), 103-118.

Kesternich, I., Siflinger, B., Smith, J.P., Winter, J.K., 2015. Individual behaviour as pathway between early-life shocks and adult health: evidence from hunger episodes in post-war Germany. Econ. J. 125 (588), F372-F393.

Martin, R.M., Gunnell, D., Pemberton, J., Frankel, S., Davey Smith, G., 2005. Cohort profile: the Boyd Orr cohort-an historical cohort study based on the 65 year follow- up of the Carnegie Survey of Diet and Health (1937-39). Int. J. Epidemiol. 34 (4), $742-749$.

Newbury, J.B., Arseneault, L., Moffitt, T.E., Caspi, A., Danese, A., Baldwin, J.R., Fisher, H.L., 2018. Measuring childhood maltreatment to predict early-adult psychopathology: comparison of prospective informant-reports and retrospective self-reports. J. Psychiatr. Res. 96, 57-64.

Reuben, A., Moffitt, T.E., Caspi, A., Belsky, D.W., Harrington, H., Schroeder, F., Danese, A., 2016. Lest we forget: comparing retrospective and prospective assessments of adverse childhood experiences in the prediction of adult health. J. Child Psychol. Psychiatry 57 (10), 1103-1112.

Van den Berg, G.J., Pinger, P.R., Schoch, J., 2016. Instrumental variable estimation of the causal effect of hunger early in life on health later in life. Econ. J. 126 (591), 465-506.

Van Hedel, K., Mejía-Guevara, I., Avendaño, M., Sabbath, E.L., Berkman, L.F., Mackenbach, J.P., van Lenthe, F.J., 2016. Work-family trajectories and the higher cardiovascular risk of American women relative to women in 13 European countries. Am. J. Public Health 106 (8), 1449-1456. 